\title{
Evaluation of the quality of pile foundations by different methods
}

\author{
Askar Zhussupbekov ${ }^{1, *}$, Ivan Morev $^{2}$, Gulzhanat Tanyrbergenova ${ }^{1}$, Nurgul Shakirova $^{1}$ \\ ${ }^{1}$ L.N.Gumilyov Eurasian National University, Kazakhstan \\ ${ }^{2}$ KGS LLP, Kazakhstan
}

\begin{abstract}
At the present time, in Astana city is going on works by construction public transport system LRT (Light Railway Transport). LRT is an overhead road with two railway lines. The first stage of construction is including construction of overhead road (bridge) with $22.4 \mathrm{~km}$ length and 18 stations. The foundation of bridge is the bored piles with cross-section of $1.0-1.5 \mathrm{~m}$ and length of 8-35 m. A design bearing capacity of pile is $4500-$ $8000 \mathrm{kN}$. Chinese drilling rigs Zoomlion was used for soil boring without casing. A polymer slurry is used to maintain the walls of boreholes in sand and gravel soils. In these conditions very important point is the integrity of concrete body of each bored piles. For checking the integrity was used two methods - the Low Strain Method and the Cross-Hole Sonic Logging. The aim of this paper is finding the advantages and disadvantages of each method which applying on testing site.
\end{abstract}

\section{Introduction}

In 2017 construction public transport system LRT (Light Railway Transport) was started in Astana city. Constructions carry out by Chinese company «China Railway Asia-Europe Construction Investment Co». The LRT is an overhead road with two railway lines. The first stage of construction includes a construction of overhead road (bridge) of 22,4 km length and 18 stations. A height of the bridge is 7-14 m above the ground. An overhead road is supported by columns through every 30 meters. The foundations of each column include 4 or 6 bored piles with cross-section of 1.0-1.5 m and length of 8-35 m. A design bearing capacity of each bored piles are $4500-8000 \mathrm{kN}$.

In order to reduce the time for construction and cost of piling works was used Chinese drilling rigs Zoomlion without casing. The polymer slurry is used to maintain the walls of boreholes in sand and gravel soils. An application of polymer slurry allow reducing time for drilling, to use less powerful drilling rigs and equipment, but at the same time increasing the risk to collapse the soil during drilling or pouring the concrete of piles. In these conditions a very important point is to control the integrity of concrete body of each bored piles. For checking integrity of bored piles were used two methods - the Low Strain Method and the Cross-Hole Sonic Logging

*Corresponding author: astana-geostroi@mail.ru 


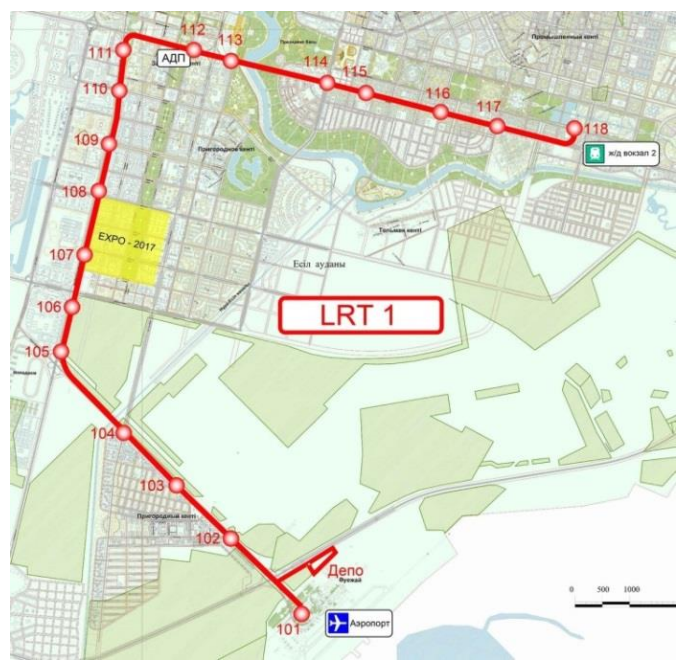

Fig. 1. Map of First Line LRT in Astana.

\section{The Integrity Testing}

Usually, we have to face the fact that on any construction site some piles may exhibit flaws. Of course, not all flaws are detrimental to the performance of the pile. Only a flaw that, because of either size or location, may detract from the pile's load carrying capacity or durability is defined as a defect. The geotechnical engineer and the structural engineer are jointly responsible to decide which flaw comprises a defect.

Two techniques currently are dominated for pile integrity testing, namely the Low Strain Method and the Cross-Hole Sonic Logging, both of them based on the sound waves interpretation (Amir et al. 2009).

\subsection{Low Strain Method}

The low strain (sonic) method for the integrity testing of piles is aimed at routinely testing on piling sites. To perform this test, a sensor (usually accelerometer) is pressed against the top of the pile while the pile is hit with a small hand-held hammer. Output from the sensor is analyzed and displayed by a suitable computerized instrument, the results providing meaningful information regarding both length and integrity of the pile.

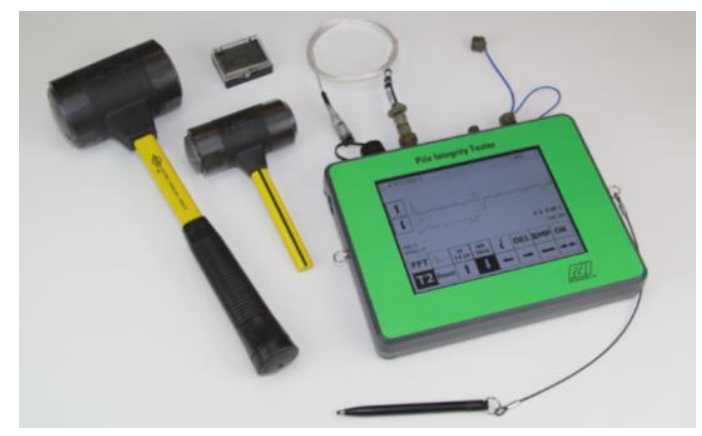

Fig. 2. Pile Integrity Tester - PIT-QV. 
The sonic test is fast and inexpensive, and needed a time less than a minute to test a given pile.

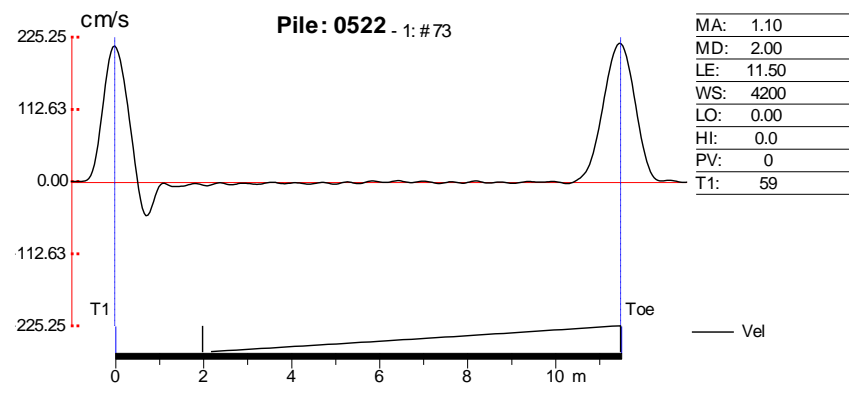

Fig. 3. A graph with normal results.

The surface vibrations are measured by means of an accelerometer attached to the top of the pile. Although the acceleration curve could be interpreted directly, integration to velocity generally enhances the record by bringing out details otherwise overlooked. The pile top acceleration signal, is therefore digitized and stored in the PIT device memory, and it is numerically integrated to produce a velocity signal. It should be noted that $\mathrm{v}$ is a particle velocity, i.e., the actual velocity of movement of the pile top surface.

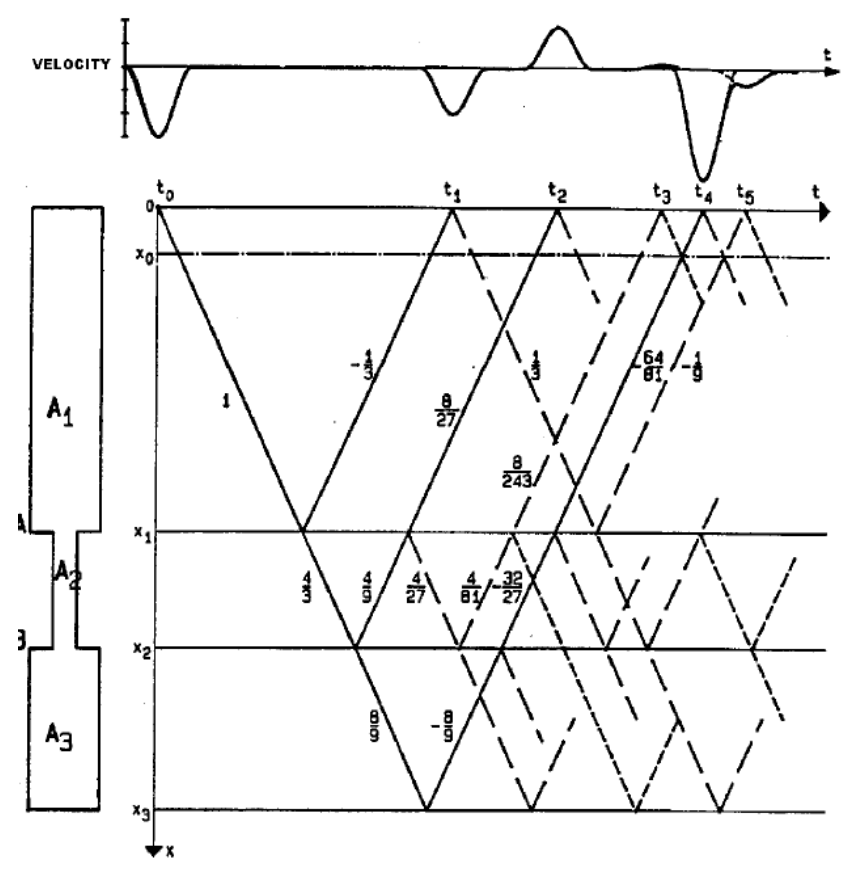

Fig. 4. Characteristics for a rod with a reduced cross-section $(\mathrm{A} 2=\mathrm{A} 1 / 2, \mathrm{~A} 3=\mathrm{A} 1)$.

\subsection{Wave Speed in Concrete}

The Impact wave speed in concrete depends on the quality of the concrete and for in-situ casted piles the curing time of the concrete. The wave speed is used to determine the length 
of the pile based on the return signal. An example of the wave speed in concrete is shown below.

Table 1. Soil Properties Used in Analysis.

\begin{tabular}{|c|c|}
\hline Concrete quality & Impact wave speed $(\mathbf{m} / \mathbf{s})$ \\
\hline Bad & $<2.700$ \\
\hline Acceptable & $2.700-3.300$ \\
\hline Good & $3.300-3.800$ \\
\hline Very good & $3.800-4.000$ \\
\hline Excellent & $4.000-4.500$ \\
\hline $\begin{array}{c}\text { Unlikely normal } \\
\text { conditions }\end{array}$ & $>4.500$ \\
\hline
\end{tabular}

\subsection{Interpretation results obtained by Low Strain Method}

An assessment by this method can give a rapid and accurate appraisal of pile integrity. An integrity test will indicate when

a pile should be investigated further but it cannot give information about any load carrying capacity of the pile.

Interpretation of the results obtained must take into account the specific pile circumstances, i.e. construction technique and localized soil conditions. An anomaly does not necessarily indicate a deficiency in the pile, but would certainly merit further investigation to establish the cause of the anomaly. Full interpretation of the signal responses must only be undertaken by fully trained personnel.

For interpretation ten classes are distinguished:

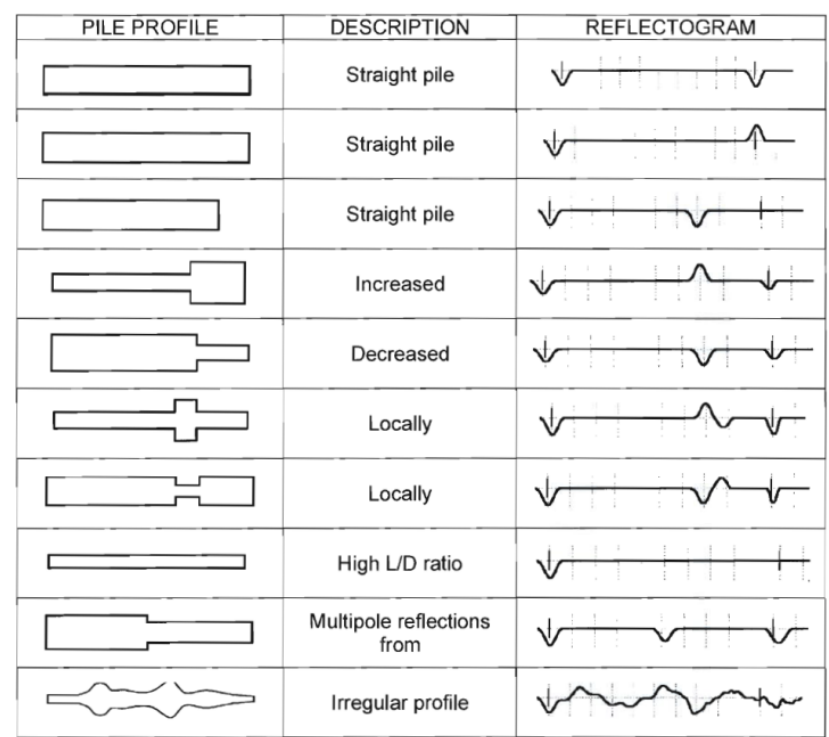

Fig. 5. Typical piles with respective reflectograms.

\subsection{Low Strain Testing Constraints}

The following items may often be detected:

- Pile length. 
- Inclusions of foreign material with different acoustic properties.

- Cracking perpendicular to the axis.

- Joints and staged concreting.

- Abrupt changes in cross section.

- Distinct changes in soil layers.

All physical measurements have limitations, and low strain (sonic) test probably has more limitations than any other test. For instance, the sonic test will normally not detect the following items:

- The toe reflection when the L/D ratio roughly exceeds 20 (In hard soils) to 60 (In very soft soils).

- Gradual changes in cross-section.

- Minor inclusions and changes in cross-section.

- Impedance changes of small axial dimension.

- Small variations in length.

- Features located below either a fully-cracked cross section or a major (1:2) change in impedance.

- Debris at the toe.

- Deviations from the straight line and from the vertical.

- Load-carrying capacity.

- The consistency of concrete cover.

- The length of reinforcement.

\subsection{Cross-Hole Sonic Logging}

The Low Strain method belongs to the external test-methods, as it accesses only the top of the pile. Ultrasonic logging, on the other hand, is intrusive and necessitates the prior installation of access tubes (usually two or more) in the pile.

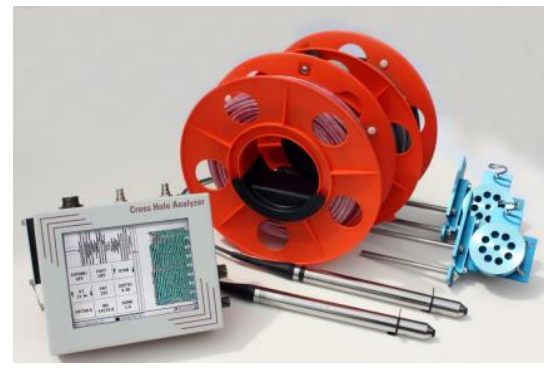

Fig. 6. Cross-Hole Sonic measuring device - CHAMP: computer, cable, depth encoders, test probes.

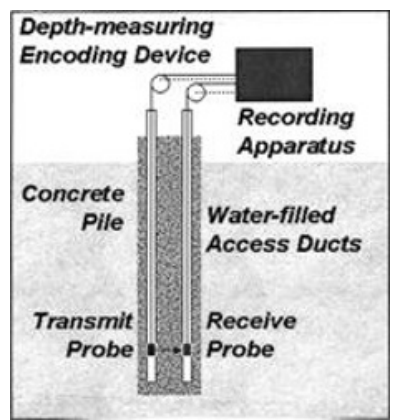

Fig. 7. Test Arrangement. 
Before the test they have to be filled with water (to obtain good coupling) and two probes are lowered inside two of the

tubes. One of these probes is an emitter and the other a receiver of ultrasonic pulses. Having been lowered to the bottom, the probes are then pulled simultaneously upwards to produce an ultrasonic logging profile. The transmitter produces a series of acoustic waves in all directions. Some of these waves do eventually reach the receiver.

The testing instrument then plots the travel time between the tubes versus the depth. As long as this time is fairly constant, it shows that there is no change in concrete quality. A sudden increase of the travel time at any depth may indicate a flaw at this depth.

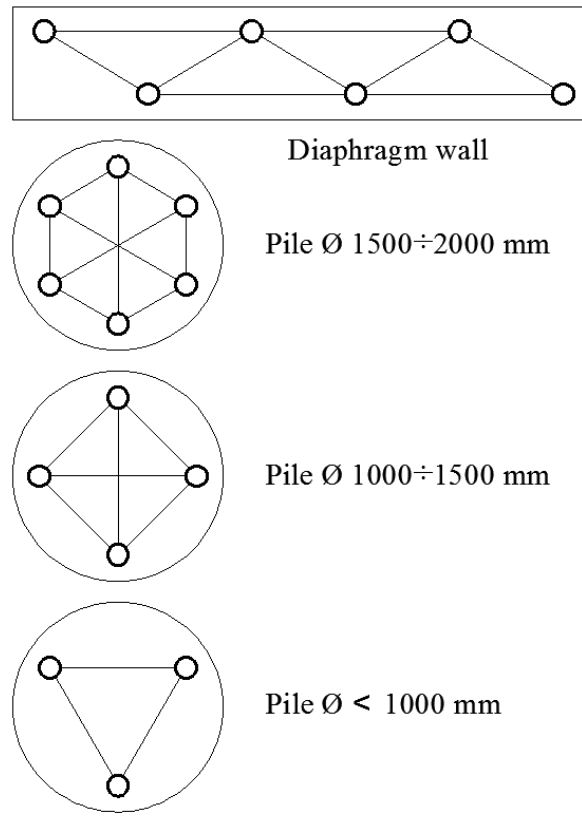

Fig. 8. Typical Access Duct Configurations.

The number of access tubes cast in the pile concrete is a function of the pile diameter, the importance of the pile and, of course, economic consideration. A good rule of thumb is to specify one tube per each $30 \mathrm{~cm}$ of pile diameter. Thus for a pile with a diameter of $1.2 \mathrm{~m}$, four tubes will normally do. For best effect, the tubes should be equally spaced inside the spiral reinforcement and rigidly attached to it by wire or spot welding. Where tubes are extended below the reinforcement cage, they have to be stabilized by suitable steel hoops.

\subsection{Cross-Hole Sonic Logging Results}

Usually the report includes presentation of Cross-Hole Sonic logs for all tested tube pairs including: depth.

- Presentation of the traditional signal peak diagram as a function of time plotted versus

- Computed initial pulse arrival time or pulse wave speed versus depth.

- Computed relative pulse energy or amplitude versus depth.

A Cross-Hole Sonic log will be presented for each tube pair. Defect zones, if any, will be indicated on the logs and their extent and location discussed in the report text. Defect zones are defined by an increase in arrival time of more than 20 percent relative to the arrival time in a nearby zone of good concrete, indicating a slower pulse velocity. 


\subsection{Tomography by the data of Cross-Hole Sonic Logging}

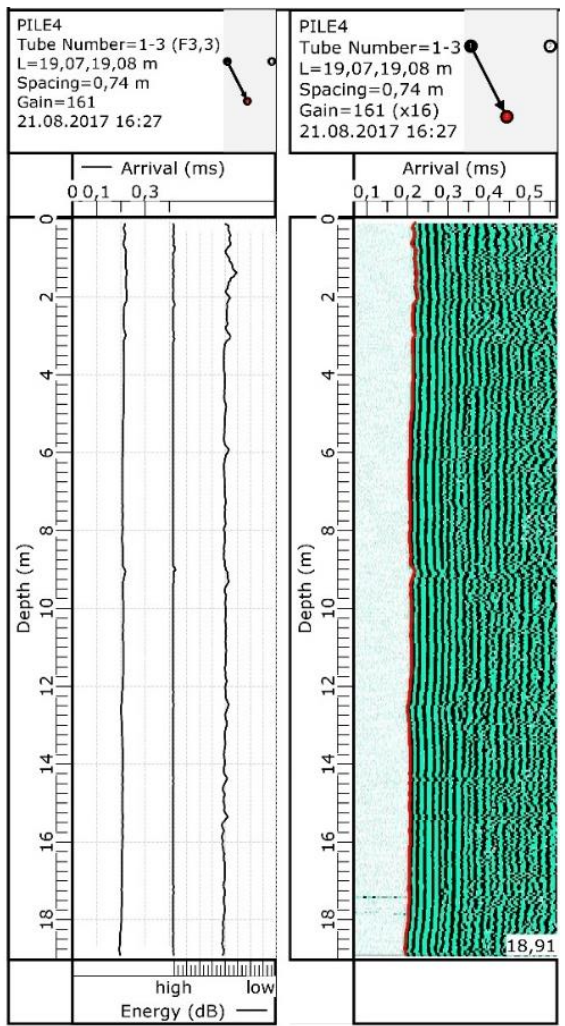

Fig. 9. Typical Ultrasonic Profile.

The same procedure, which is carried out in two dimensions on a single profile, can be used in three dimensions for the whole pile. In this case, the pile is divided into elementary voxels, or volume pixels, this process is usually called a tomography.
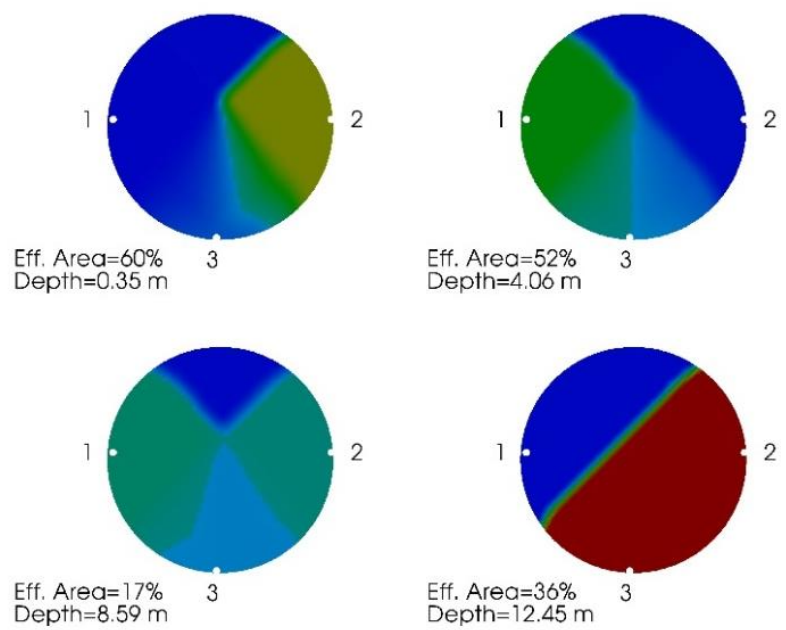

Fig. 10. Horizontal cross-sections of pile in PDI-TOMO software. 
Tomography is a mathematical procedure that is applied to Crosshole Sonic Logging (CSL) data, providing the user with a visual image of a shaft's internal defects. The procedure involves solving a system of equations based on First Arrival Times (FAT) in order to calculate wave speeds at various points within the shaft. Tomography wave speeds distributed throughout the shaft are directly proportional to density, indicating concrete quality. PDI-TOMO is an extension of the CHA-W software designed for superior tomographic analysis results from CHAMP data with increased efficiency for the user.

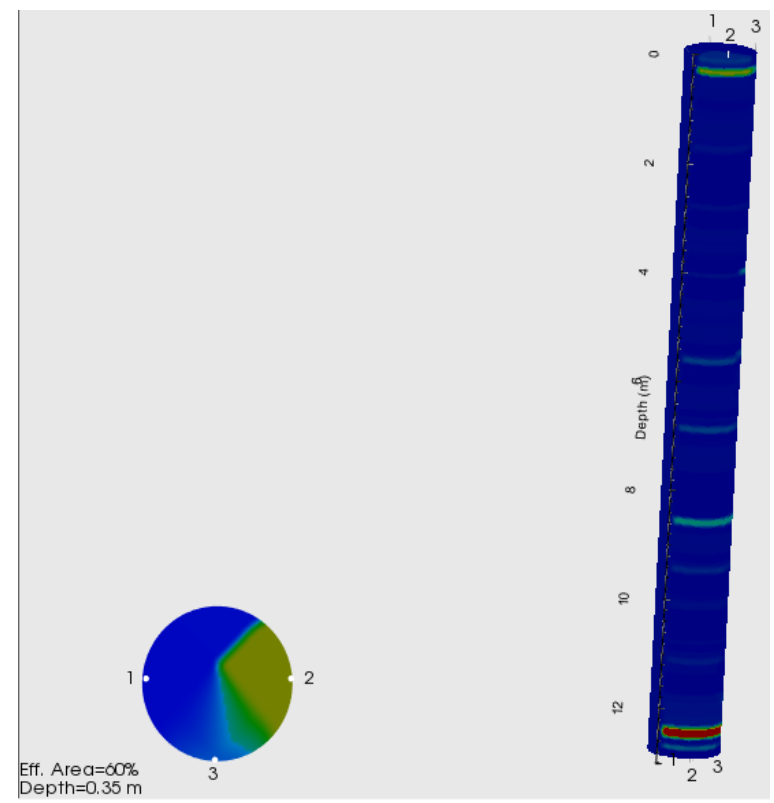

Fig. 11. Three-dimensional visualization in PDI-TOMO software.

PDI-TOMO software features:

- Provides a more precise location, shape and size of defective areas within a shaft.

- Offers an intuitive visual identification of the damaged areas and generates easily comprehensible and professional outputs for the consumer of the CSL reports.

- Provides a valuable add-on service for the testing engineer.

\subsection{Cross-Hole Sonic Testing Constraints}

The Cross-Hole Sonic Test will normally detect the following items:

- Finds multiple defects, depth and quadrant.

- Finds "soft bottoms" if tubes go to bottom.

- Finds voids better than soil inclusions.

- Finds larger defects easier than small defects.

- Waterfall, FAT (First arrival time), \& energy all help find defect.

- Not sensitive to surrounding soils or pile length.

The Cross-Hole Sonic Test will normally not detect the following items:

- Cannot find diameter changes or bulges.

- If too few tubes, can miss a defect.

- Can find defect on direct path.

- Cannot find defect outside cage.

- Major diagonal defects more difficult to find.

- Need more than 4 tubes for $1500 \mathrm{~mm}$ pile (recommend 6 tubes for shaft this size). 


\subsection{Comparison test results obtained by two methods}

In 2017 at the construction site of LRT in Astana city, more than 700 bored piles tested for checking the integrity by using two methods: $25 \%$ by Cross-Hole Sonic Logging and other $75 \%$ by Low Strait Test. A technical assignment for integrity testing piles is:

- if one foundation of the bridge consists of four bored piles, then one pile is tested by Cross-Hole Sonic Logging and other three piles tested by Low Strait Test.

- if one foundation of the bridge consists of six bored piles, then two pile is tested by Cross-Hole Sonic Logging and other four piles tested by Low Strait Test.

One of the tested pile PR16-2 contained a serious defect of integrity.
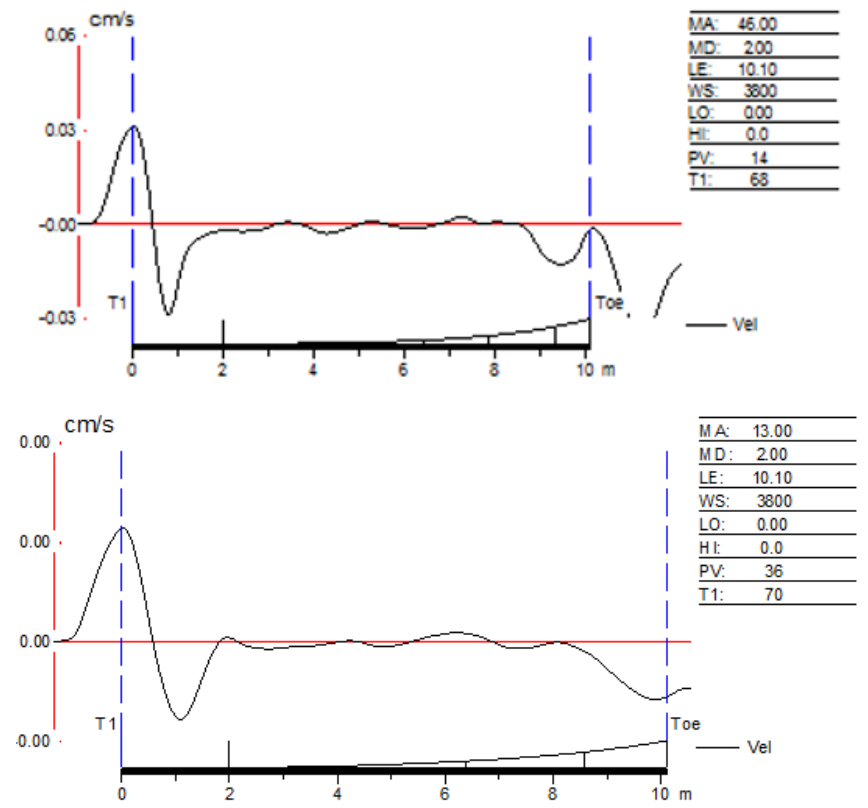

Fig. 12. Two reflectograms of one bored pile PR16-2 obtained by Pile Integrity Tester - PIT-QV.

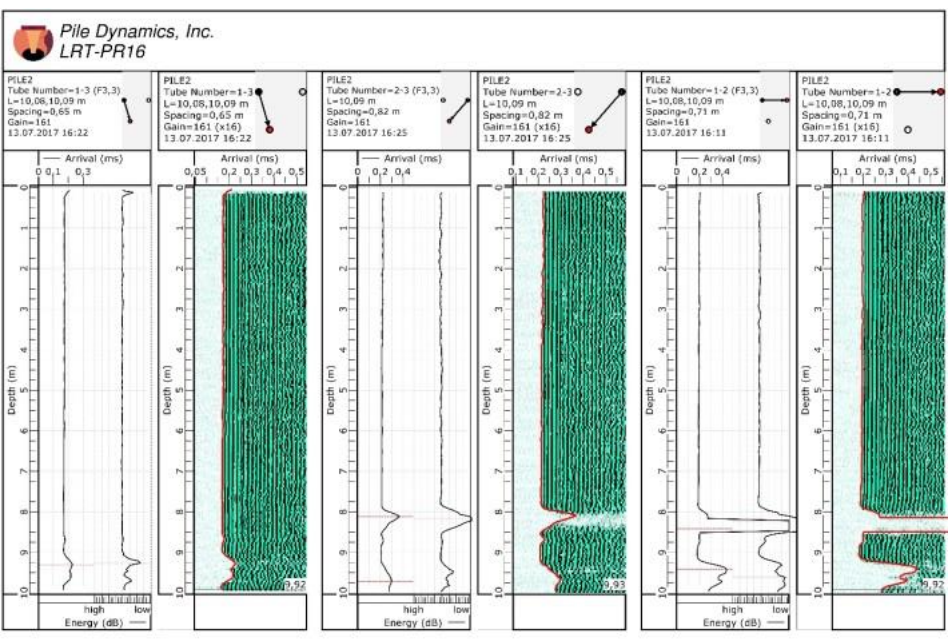

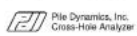

Fig. 13. Three Ultrasonic Profile of one pile PR16-2. 

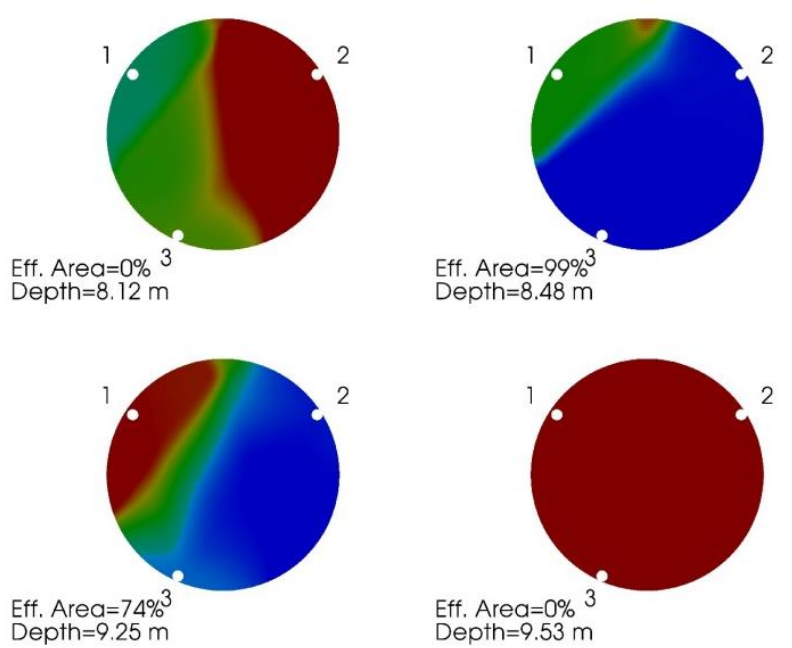

Fig. 14. Horizontal cross-sections of pile PR16-2 in PDI-TOMO software.
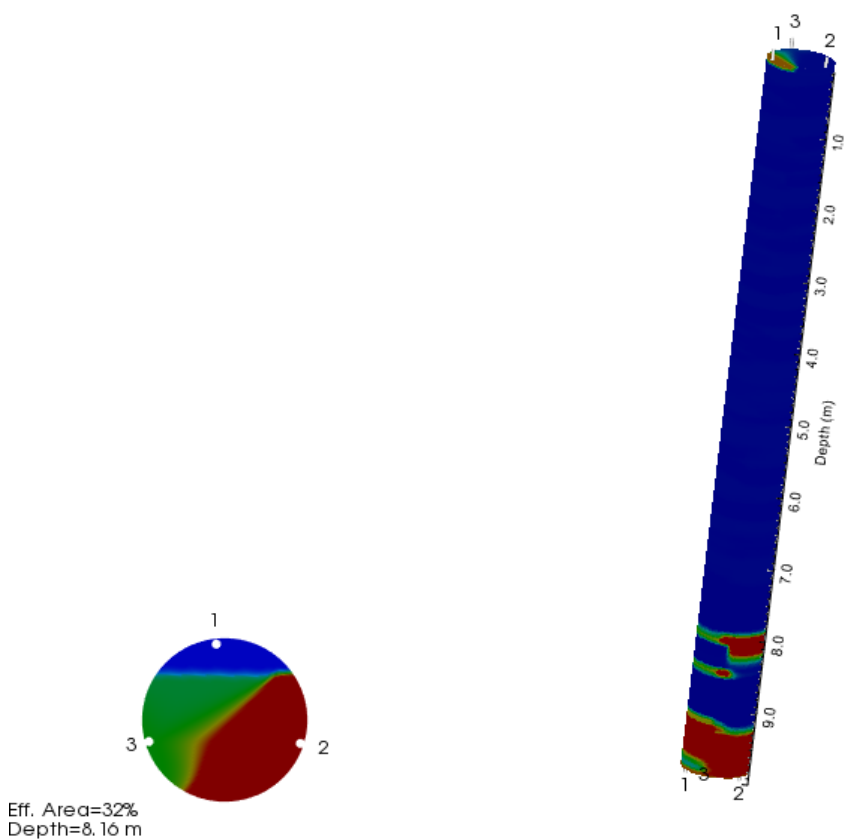

Fig. 15. Three-dimensional visualization in PDI-TOMO software for bored pile PR16-2.

Analyzing the data obtained by Low Strain Test (Fig. 11) we can say only that at the depth $8.5 \mathrm{~m}$ this pile has crack and its cross-section is decreasing.

Analyze the data of Cross-Hole Sonic Test can show 3D location of cracks, approximately size of cracks, effective cross-section of pile at any depth. Cross-Hole Sonic Test provide more useful information about integrity and allows the engineer to evaluate the seriousness of the problem and the possibility of using this pile in foundation. 


\section{Conclusions}

The cost of a quality control program for each construction site is very reasonable, and in any case much lower than the potential loss caused by an undetected defect of foundation. The Low Strain test is a powerful quality-control tool, not so expensive and need about one minute for application but we must never forget that it is not omnipotent. Since the sonic method is based on the use of stress-waves, it can identify only those pile attributes that influence wave propagation and have a fairly large size.

The Cross-Hole Sonic Logging method more accurate, allow estimating the size and position of cracks. Although the access tubes introduce an extra expense item, the cross-hole test compensates for this by allowing the testing equipment to approach potential flaws. An additional advantage of this test is the enhanced resolution: while the sonic test uses a wavelength of at least two meters, the cross-hole method utilizes ultrasonic frequencies, with typical wave lengths of 50 to $100 \mathrm{~mm}$. Since resolution is strongly dependent on the wave length, the cross-hole method enables us to detect much smaller flaws with high accuracy.

\section{Acknowledgements}

The authors would like to express acknowledgment to the KGS, LLP for their contribution to organize testing on the construction site.

\section{References}

1. M.A. Joram, Pile Integrity Testing (Israel, 2009)

2. ASTM Standard D 5882, Standard Test Method for Low Strain Impact Integrity Testing of Deep Foundations (ASTM International, West Conshohocken, 2000)

3. ASTM Standard D 6760, Standard Test Method for Integrity Testing of Concrete Deep Foundations by Ultrasonic Crosshole Testing (ASTM International, West Conshohocken, 2002)

4. B. White, M. Nagy, R. Allin, Proc. of the 8th International Conf. of Application of Stress Wave Theory to Piles, 471-476 (2008)

5. F.C. Bungenstab, J.W. Beim, Continuous Flight Auger (CFA) Piles - A Review of the Execution Process and Integrity Evaluation by Low Strain Test, IOS Press, 414-421 (2015)

6. N. Massoudi, W. Teferra, Proceedings of the Fifth Int. Conf. on Case Histories in Geotechnical Engineering, 1-6 (2004) 